\title{
Penerapan Wireless Distribution System (WDS) Mesh Untuk Optimasi Cakupan Area Wi-Fi di UM Jember
}

\author{
Achmad Riyadus Sholikhin ${ }^{1}$, Taufiq Timur Warisaji ${ }^{2}$, Triawan Adi Cahyanto ${ }^{3}$ \\ ${ }^{1}$ Jurusan Teknik Informatika, Fakultas Teknik, Universitas Muhammadiyah Jember, riyadus.93@gmail.com \\ ${ }^{2}$ Jurusan Manajemen Informatika, Fakultas Teknik, Universitas Muhammadiyah Jember, taufiqtimur@unmuhjember.ac.id \\ 3Jurusan Teknik Informatika, Fakultas Teknik, Universitas Muhammadiyah Jember, triawanac@unmuhjember.ac.id
}

\begin{tabular}{|c|c|}
\hline Keywords: & ABSTRACT \\
\hline $\begin{array}{l}\text { Wireless Distribution System, } \\
\text { Mesh Topology, } \\
\text { Wireless Network, } \\
\text { Coverage Area Optimization, } \\
\text { Access Point, }\end{array}$ & $\begin{array}{l}\text { One very rapid change in computer networks is the use of Wireless Local Area } \\
\text { Network (WLAN) to access systems both locally and the internet. One way to add an } \\
\text { Access Point (AP) so as not to change the configuration of the running software is } \\
\text { use the Wireless Distribution System Mesh (WDS) network. The use of WDS mesh } \\
\text { at Universitas Muhammmadiyah Jember (UM Jember) enables a slightly different } \\
\text { wireless configuration to reduce the connection loss in the user due to the wireless } \\
\text { network area coverage. One step is use AP devices into one unit to handle the case of } \\
\text { a connection break by utilizing a network service that is WDS Mesh. WDS Mesh can } \\
\text { cover Wi-Fi areas at UM Jember, and the results of testing and analysis of client } \\
\text { devices for APs that have been configured WDS Mesh with parameters Signal } \\
\text { Strength, CCQ, Signal to Noise Ratio Ratio, Throughput is Excellent. }\end{array}$ \\
\hline
\end{tabular}

Kata Kunci

Sistem Nirkabel Terdistribusi, Topologi Mesh,

Jaringan Nirkabel,

Optimasi Cakupan Area,

Titik Akses,

\begin{abstract}
ABSTRAK
Salah satu perubahan yang sangat pesat di dalam jaringan komputer adalah penggunaan wireless LAN (WLAN) untuk mengakses jaringan baik lokal maupun internet. Salah satu cara penambahan Access Point (AP) yang tidak mengubah konfigurasi software yang telah di gunakan yaitu menggunakan jaringan Wireless Distribution System (WDS) Mesh. Penggunaan WDS mesh di Universitas Muhammadiyah Jember (UM Jember) memungkinkan konfigurasi wireless yang sedikit berbeda agar dapat mengurangi terputusnya koneksi pada pengguna karena jangkauan area jaringan wireless. Salah satu langkah adalah dengan menggunakan beberapa perangkat Acesss Point menjadi satu kesatuan untuk menangani kasus terputusnya koneksi dengan memanfaatkan service jaringan yaitu WDS Mesh. WDS Mesh mampu meng-coverage area Wi-Fi di UM Jember dan hasil ujicoba serta analisa device client terhadap AP yang sudah dikonfigurasi sebagai WDS Mesh dengan parameter Signal Strength, CCQ, Signal to Noise Ratio Ratio, Throughput adalah Excellent (Bagus).
\end{abstract}

\section{Korespondensi Penulis:}

Achmad Riyadus Sholikhin,

Jurusan Teknik Informatika, Fakultas Teknik, Universitas Muhammadiyah Jember

Jalan Karimata 49 Jember

Email: riyadus.93@gmail.com

\section{PENDAHULUAN}

Salah satu perubahan yang sangat pesat di dalam jaringan komputer adalah penggunaan Wireless LAN (WLAN). Kemudahan penggunaan yang ditawarkan menjadi daya tarik tersendiri bagi pengguna komputer untuk mengakses suatu jaringan dan internet [1]. Terdapat suatu masalah yang akan dihadapi apabila proses komunikasi menggunakan WLAN. Salah satunya adalah masalah cakupan area hotspot dan koneksi antar Access Point (AP). Hotspot memiliki cakupan area terbatas, bergantung pada spesifikasi AP yang digunakan. Untuk memperluas area cakupan, perlu penambahan perangkat AP sesuai kebutuhan [2]. Penambahan AP ini diharapkan tidak mengubah konfigurasi software yang telah digunakan. Selain itu, diharapkan juga dapat digunakan sebagai sarana untuk roaming bagi pengguna [3]. Salah satu teknik penambahan AP agar tidak merubah konfigurasi software yang telah 
di gunakan yaitu menggunakan jaringan WDS Mesh. WDS Mesh memungkinkan untuk konfigurasi Wireless yang berbeda untuk meningkatkan jangkauan area menggunakan beberapa perangkat AP menjadi suatu kesatuan [4]. Jenis topologi jaringan di UM Jember yang tepat agar memberikan solusi atas keluhan mahasiswa dan dosen yaitu dengan menerapkan topologi WDS Mesh [5]. Desain perangkat pada topologi jaringan di UM Jember memiliki beberapa gedung, dimana setiap gedung dan lantainya terdapat sebuah AP yang diletakkan secara horizontal dan vertikal yang berfungsi mencakup seluruh area hotspot [6]. Topologi tersebut menyerupai sebuah jala atau jaring, oleh karena itu, untuk mengatasi masalah tersebut digunakanlah WDS Mesh.

\section{METODE PENELITIAN}

\subsection{Pengumpulan Data}

Pengumpulan data pada penelitian ini dilakukan dengan cara wawancara. Wawancara dianggap sebagai tahap pengkajian terhadap masalah yang diteliti dengan cara mewawancarai pihak yang mengetahui struktur jaringan, serta bagaimana penyelesaian masalah yang optimal. Wawancara dilakukan kepada pimpinan UPT Pusat Data dan Informasi (PDI) sebagai unit yang menangani masalah TI yang juga termasuk jaringan eksternal (internet) yang ada di UM Jember. Berdasarkan keterangan dari pimpinan UPT PDI disimpulkan bahwa UM Jember sepakat untuk menerapkan metode WDS Mesh. Penerapan WDS ini diharapkan dapat meningkatkan layanan internet yang ada pada UM Jember yang sebelumnya masih tidak maksimal menjangkau klien di lingkungan kampus.

\subsection{Studi Literatur}

Pendalaman materi di dapatkan dengan cara pencarian informasi melalui internet dan buku yang berkaitan dengan WDS, ada beberapa mode operasional yang penting untuk dipahami, diantaranya [7]:

1. Dynamic WDS interface adalah apabila proses pembentukan hubungan antara AP satu dengan AP lainnya dilakukan secara dynamic/secara otomatis akan segera dibuat.

2. Static WDS interface adalah apabila proses pembentukan hubungan antara AP satu dengan AP yang lainnya harus dilakukan secara manual, dengan memasukkan Media Access Control (MAC) address AP yang lainnya.

3. Dynamic mesh interface adalah hampir sama dengan mode dynamic tetapi menggunakan protokol HWMP+ (penyempurnaan WDS standar).

4. Static mesh interface adalah cara kerja dan kegunaannya hampir sama dengan mode static, tetapi sudah menggunakan protokol baru sebagai penyempurnaan WDS standar yaitu protokol HWMP+.

\subsection{Perancangan}

Tahap Perancangan merupakan mode perancangan terhadap lokasi pada Wireless mana saja yang akan di buat menjadi WDS Mesh di UM Jember.

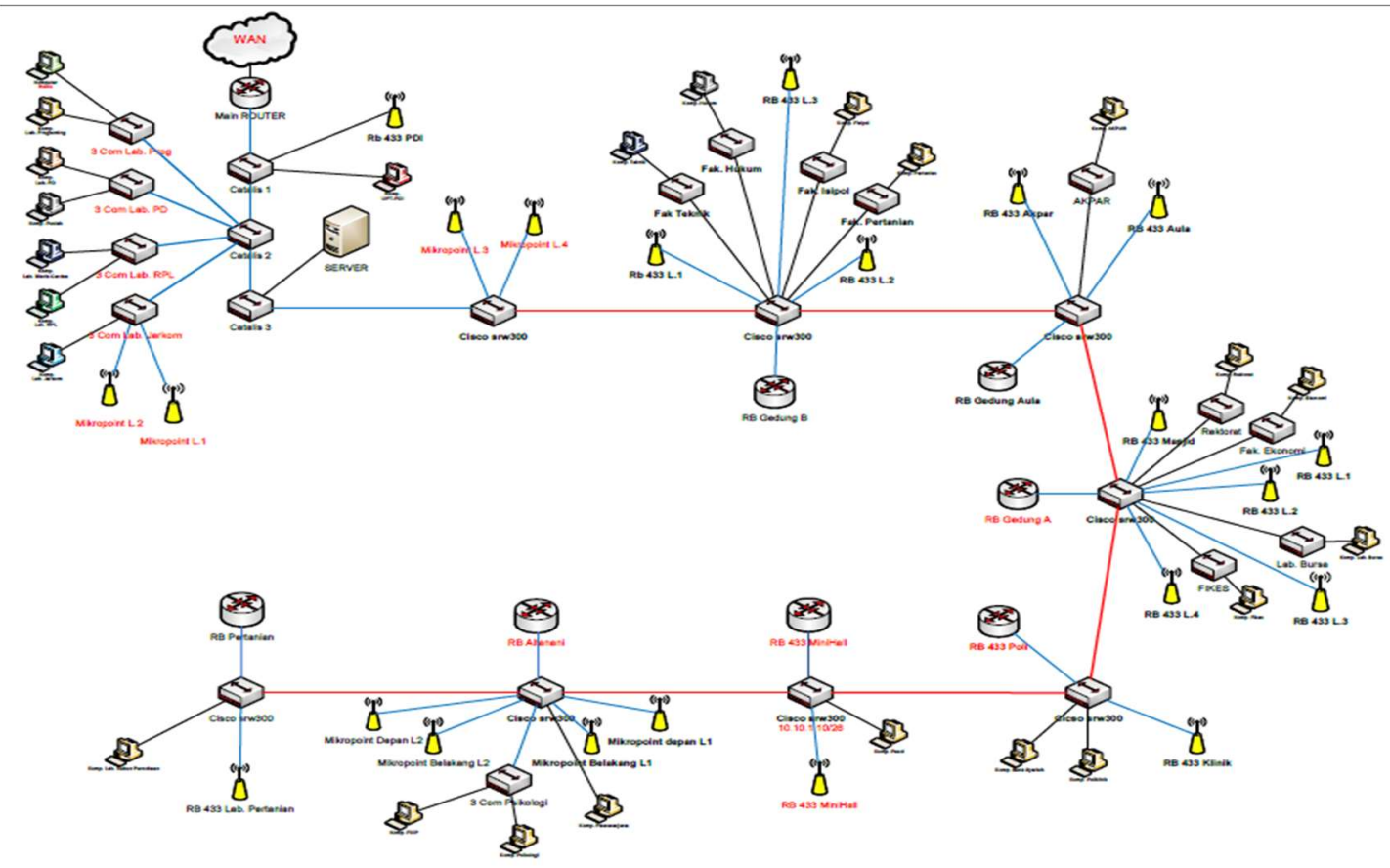

Gambar 1. Topologi yang akan dikonfigurasi menjadi WDS 
Gambar 1 diatas menjelaskan beberapa keterangan tentang topologi jaringan yang dibuat untuk mode WDS pada UM Jember. Implementasi ini berfokus pada tahapan yang akan dikonfigurasi pada setiap AP yang akan dioptimalkan menjadi WDS sehingga nantinya dapat meningkatkan area jangkauan dan koneksi.

\subsection{Analisis}

Analisis yang digunakan dalam implementasi WDS adalah dengan merancang skema jaringan serta menguji kinerja WDS Mesh yang sudah dibangun. WDS adalah sistem yang memungkinkan interkoneksi nirkabel jalur akses dalam jaringan IEEE 802.11 [8]. Hal ini memungkinkan jaringan nirkabel untuk diperluas menggunakan beberapa jalur akses tanpa persyaratan tradisional untuk backbone kabel [9], [10]. Penggunaan WDS ini memungkinkan komunikasi data melewati beberapa AP seperti halnya sebuah jaringan ethernet yang dapat diibaratkan AP tersebut sebagai sebuah switch [11].

\subsection{Mekanisme Pengujian}

Pengujian dilakukan pada minilab yang dibangun menggunakan 3 buah Router Mikrotik RouterBoard 9512nd yang saling terhubung membentuk topologi Mesh. Skenario pengujian dilakukan secara berkala dengan menghubungkan setiap AP pada jarak 1 meter, 3 meter, 5 meter dan 8 meter secara berpindah-pindah dengan parameter yang digunakan sebagai indikator pengujian adalah Signal Strength, Throughput, CCQ dan Signal to Noise Ratio yang bertujuan untuk melihat kualitas jaringan menggunakan WDS berbasis topologi Mesh. Berikut ini penjelasan lebih lanjut mengenai keempat parameter pengujian yang digunakan.

\section{Parameter Signal Strength}

Signal strength (kekuatan sinyal) merupakan parameter yang menentukan kehandalan suatu Wi-Fi berdasarkan tingkat kekuatan sinyal [12]. Semakin kuat suatu sinyal maka akan semakin baik dan handal konektivitas perangkat tersebut. Kekuatan sinyal pada perangkat seperti $W i-F i$ ditunjukkan dengan besaran $d B m$. Berikut ini merupakan kategori rentang nilai yang menjelaskan kekuatan sinyal berdasarkan kualitas [13].

Excellent berada pada rentang nilai -57 sampai $0 \mathrm{dBm}$

Good berada pada rentang nilai -75 sampai $-58 \mathrm{dBm}$

Fair berada pada rentang nilai -85 sampai $-76 \mathrm{dBm}$

Poor berada pada rentang nilai -95 sampai $-86 \mathrm{dBm}$

Untuk mencari nilai signal strength, dapat menggunakan perangkat lunak homedale [14].

2. Parameter Throughput

Parameter Throughput merupakan kecepatan rata-rata data yang diterima dalam selang waktu pengamatan tertentu [15]. Rumus mencari nilai throughput adalah sebagai berikut:

$$
\text { Throughput }=\frac{\text { Jumlah data yang diterima }}{\text { Waktu pengiriman data }}
$$

Keterangan:

Nilai jumlah data yang diterima dan nilai waktu pengiriman data dapat diperoleh dengan mengamati paket data yang diperoleh dengan perangkat lunak wireshark.

\section{Parameter CCQ}

Parameter CCQ (Client Connection Quality) merupakan persentase yang menunjukkan efektivitas bandwidth yang digunakan terhadap bandwidth maksimum yang tersedia. Persentase $C C Q$ berbanding lurus dengan throughput yang didapatkan dari suatu sambungan Wi-Fi. Semakin bagus nilai persentase CCQ maka semakin tinggi throughput yang didapatkan. Berikut ini merupakan kategori nilai parameter CCQ [16] :

Sangat baik berada pada rentang nilai $80 \%$ sampai $100 \%$

Baik berada pada rentang nilai $60 \%$ sampai $79 \%$

Cukup berada pada rentang nilai $40 \%$ sampai $59 \%$

Buruk berada pada rentang nilai $0 \%$ sampai $39 \%$

4. Parameter Signal to Noise Ratio

Parameter Signal to Noise Ratio (SNR) merupakan pengujian yang dilakukan untuk mengukur rasio perbandingan sinyal yang diterima dengan gangguan (interferensi) yang berada disekitar perangkat. Kualitas dari Signal to Noise Ratio dibagi kedalam empat kategori, berikut ini [8]:

SNR Excellent Signal $=>40 \mathrm{~dB}$, Cepat terkoneksi, Throughput maksimal dan stabil.

SNR Very Good Signal = $25 \mathrm{~dB}-40 \mathrm{~dB}$, Terkoneksi baik, Throughput maksimal.

SNR Low Signal $=15 \mathrm{~dB}-24 \mathrm{~dB}$, Terkoneksi baik, Throughput tidak maksimal.

SNR Very Low Signal $=10 \mathrm{~dB}-14 \mathrm{~dB}$, Koneksi tidak terlalu stabil, Throughput rendah.

SNR No Signal $=5 \mathrm{~dB}-9 \mathrm{~dB}$, Koneksi sangat tidak stabil, Throughput sangat rendah. 
Perhitungan nilai SNR pada penelitian ini menggunakan perangkat lunak homedale karena perangkat tersebut mampu memberikan nilai yang akurat sesuai dengan kualitas sinyal perangkat ketika diuji [14].

\section{HASIL DAN ANALISIS \\ 3.1 Proses Pengujian}

Proses pengujian bertujuan untuk mengetahui kinerja WDS Mesh dengan indikator pengujian diantaranya adalah CCQ, Signal to Noise Ratio, Throughput, Signal Strength pada AP yang ada di UM Jember sebagai uji untuk menentukan hasil WDS Mesh.

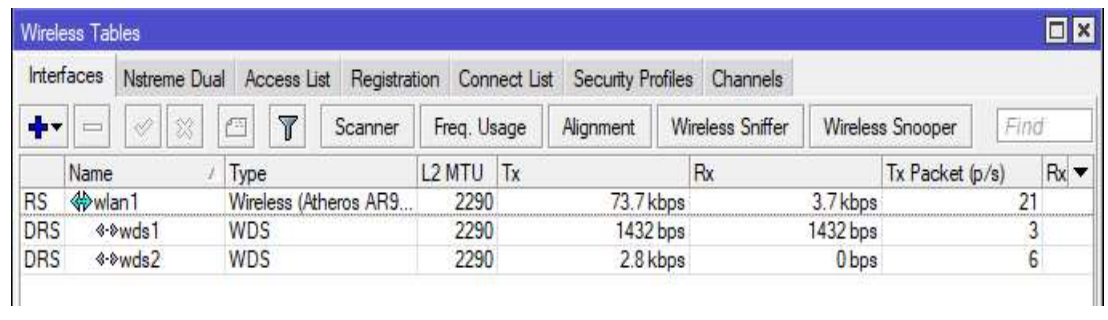

Gambar 2. Status Wireless WDS Mesh

Gambar 2. menunjukkan konfigurasi WDS Mesh berhasil dengan indikator name wds1 dan wds2 serta statusnya DRSA (Dynamic Running Slave Active).

\subsection{Pengujian Antar $\boldsymbol{A P}$}

Perhitungan jarak antar $A P$ dilakukan untuk melihat $T x / R x . T x$ (transmitter) merupakan jalur yang dilalui dalam mengirim data antar perangkat sedangkan $R x$ (received) merupakan jalur penerimaan data (perpindahan data) antar perangkat. Nilai $T x / R x$ dari $A P$ digunakan sebagai bahan untuk membandingkan hasil perhitungan, apakah sesuai dengan standar yang ada, dan berikut adalah hasil uji $T x / R x$ pada beberapa $A P$ :

Tabel 1. Contoh Pengujian antar $A P$

\begin{tabular}{lcc}
\hline \multicolumn{3}{c}{ Jarak Antar $A P$} \\
\hline Nama AP & Tx & Rx \\
\hline AP 1,4 dengan 1,5 & -78 & -70 \\
AP 1,4 dengan 2,4 & -74 & -68 \\
AP 1,4 dengan 2,5 & -86 & -92 \\
\hline
\end{tabular}

Dari tabel diatas, nilai 4 dan 5 merupakan nama $A P$ yang jaraknya terbilang jauh dari posisi $A P 1, A P 2$ maupun $A P$ 3. Berdasarkan nilai tersebut maka koneksi antar $A P$ dikatakan kurang baik karena nilai rata-rata $\mathrm{Tx} / \mathrm{Rx}$ diatas -70 karena jika minusnya semakin jauh dari angka 0 maka akan semakin kuat sinyalnya. Oleh karena itu, jika mode WDS antar AP saling terkoneksi, client tidak perlu mengkoneksikan kembali karena device dari client akan berpindah secara otomatis sebab semua $A P$ sudah saling terkoneksi

\subsection{Grafik Hasil Ujicoba Terhadap Pengujian Kinerja $A P$ 1, $A P 2$ dan $A P 3$}

Pengujian menggunakan device ini bertujuan untuk mengetahui nilai dari CCQ, Signal to Noise Ratio, Throughput, Signal Strength pada $A P$ dengan jarak pengujian 1 meter, 3 meter, 5 meter dan 8 meter dari $A P$, dan berikut adalah hasil dari pengujian device terhadap WDS Mesh. CCQ dikatakan bagus apabila persentasenya semakin tinggi, Signal to Noise Ratio dikatakan Excellent ketika nilainya lebih dari 40 dB, Throughput dikatakan bagus jika nilainya semakin tinggi, Signal Strength dikatakan Excellent jika bernilai antara -57 dBm sampai -10 $\operatorname{dBm}(75 \%-100 \%)$ 


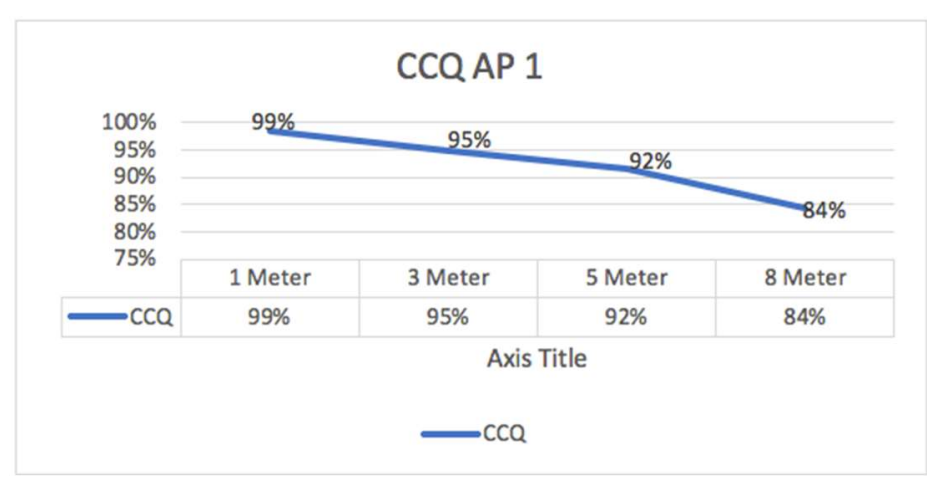

Gambar 3. Grafik CCQ AP 1

Hasil ujicoba mengacu terhadap grafik diatas, menjelaskan bahwa nilai $C C Q$ device terhadap $A P$ 1. Jarak 1 meter sebesar 99\%, jarak 3 meter sebesar 95\%, jarak 5 meter sebesar 92\% dan jarak 8 meter sebesar $84 \%$.

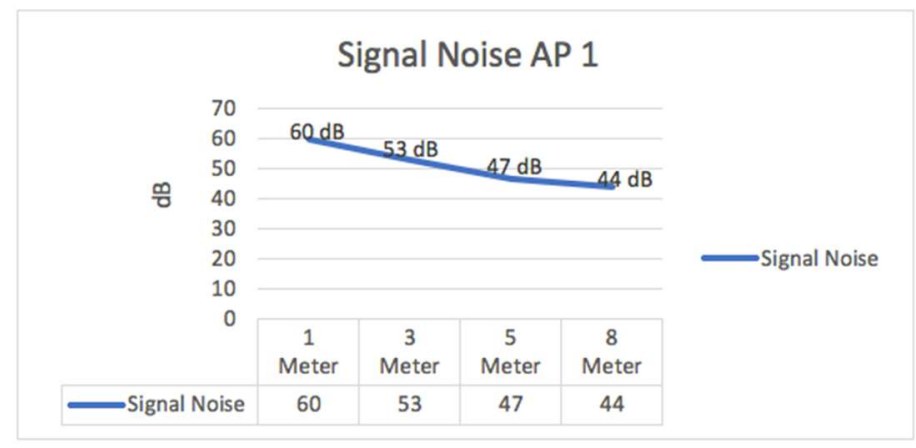

Gambar 4. Grafik Signal to Noise Ratio AP 1

Berdasarkan hasil ujicoba, skenario pengujian yang sudah dilakukan akan mendapatkan nilai Signal to Noise Ratio device terhadap AP 1. Jarak 1 meter sebesar $60 \mathrm{~dB}$, jarak 3 meter sebesar $53 \mathrm{~dB}$, jarak 5 meter sebesar $47 \mathrm{~dB}$ dan jarak 8 meter sebesar $44 \mathrm{~dB}$.

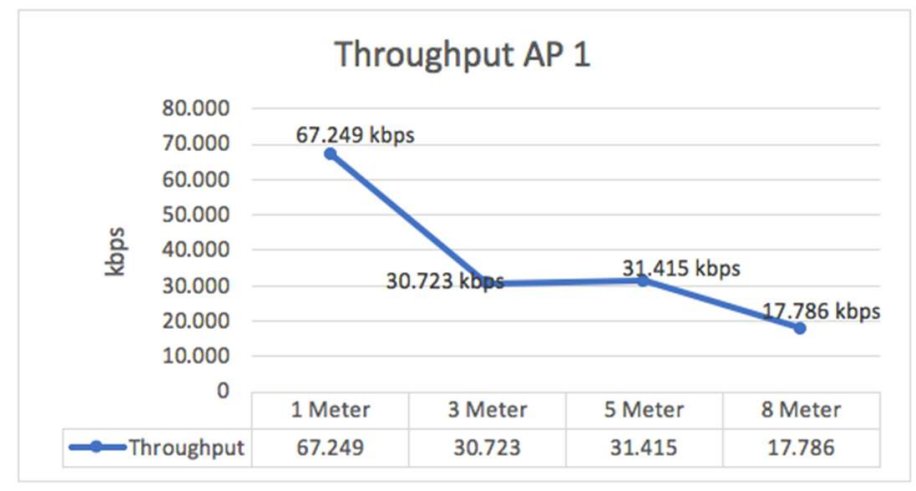

Gambar 5. Grafik Throughput AP 1

Hasil ujicoba menurut grafik diatas, akan memperoleh nilai throughput device terhadap AP 1. Jarak 1 meter sebesar 67,249 kbps, jarak 3 meter sebesar 30,723 kbps, jarak 5 meter sebesar 31,415 kbps dan jarak 8 meter sebesar 17,786 kbps. 


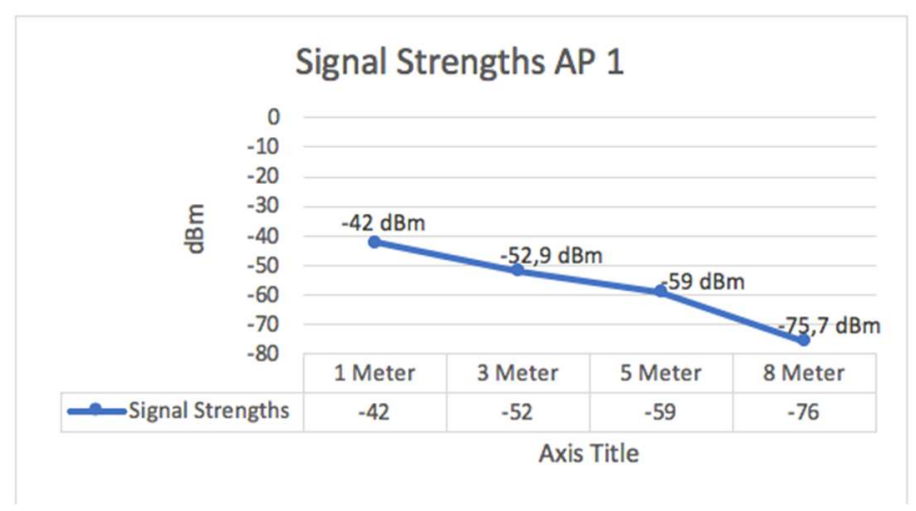

Gambar 6. Grafik Signal Strenght AP 1

Berdasarkan hasil ujicoba yang dilakukan dapat dilihat pada grafik diatas, untuk perolehan nilai Signal Strength device terhadap AP 1 . Jarak 1 meter sebesar $-42 \mathrm{dBm}$, jarak 3 meter sebesar $-52,9 \mathrm{dBm}$, jarak 5 meter sebesar $-59 \mathrm{dBm}$ dan jarak 8 meter sebesar $-75,7 \mathrm{dBm}$.

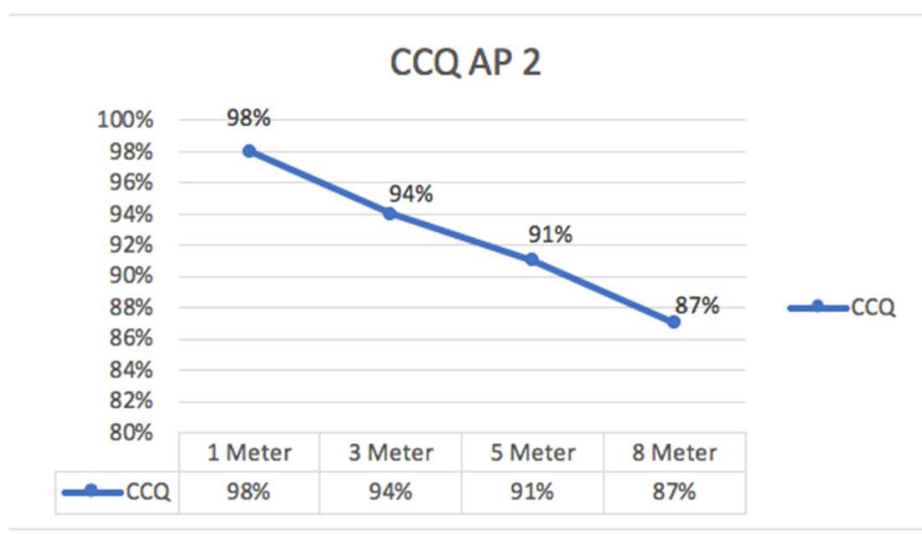

Gambar 7. Grafik CCQ AP 2

Hasil ujicoba sesuai keterangan grafik diatas, menjelaskan nilai $C C Q$ device terhadap AP 2. Jarak 1 meter sebesar $98 \%$, jarak 3 meter sebesar 94\%, jarak 5 meter sebesar $91 \%$ dan jarak 8 meter sebesar $87 \%$.

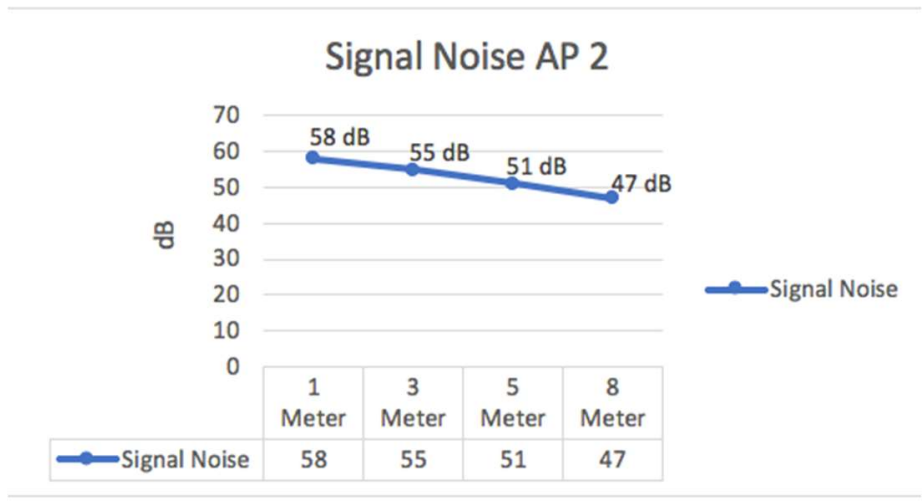

Gambar 8. Grafik Signal to Noise Ratio AP 2

Dari hasil ujicoba yang dilakukan dapat dilihat pada grafik diatas nilai Signal to Noise Ratio device terhadap AP 2. Jarak 1 meter sebesar $58 \mathrm{~dB}$, jarak 3 meter sebesar $55 \mathrm{~dB}$, jarak 5 sebesar meter $51 \mathrm{~dB}$ dan jarak 8 meter sebesar $47 \mathrm{~dB}$. 


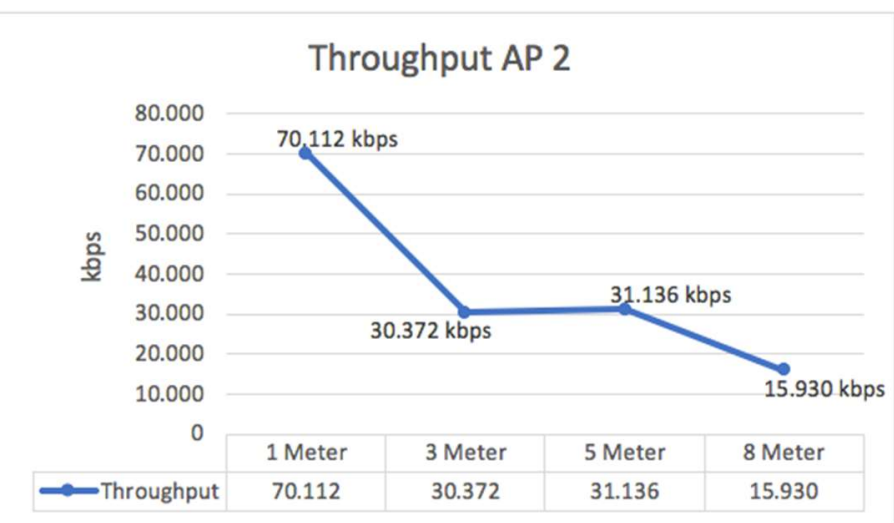

Gambar 9. Grafik Throughput AP 2

Menurut hasil ujicoba yang dilakukan, nilai throughput device terhadap AP 2 sesuai skenario memiliki nilai yang berbeda-beda. Jarak 1 meter sebesar 70,122 kbps, jarak 3 meter sebesar 30,372 kbps, jarak 5 meter sebesar 31,136 kbps dan jarak 8 meter sebesar 15,930 kbps.

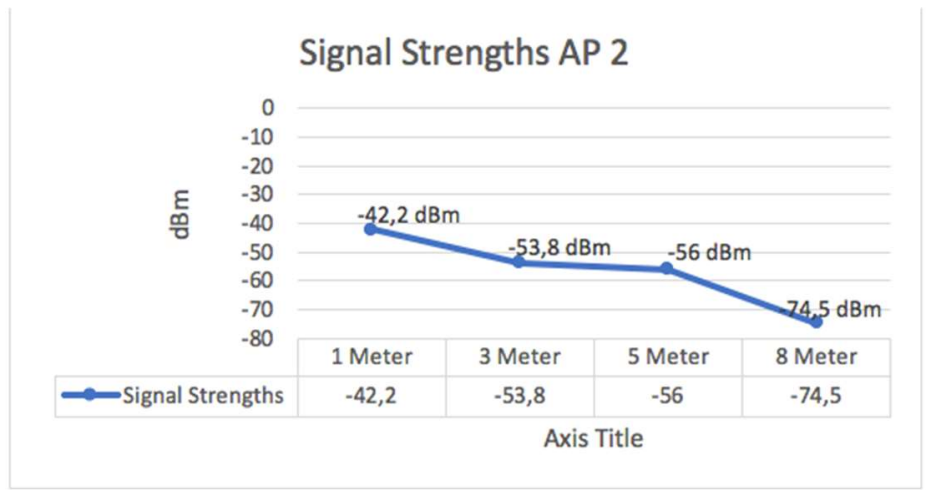

Gambar 10. Grafik Signal Strengths AP 2

Hasil ujicoba menurut grafik diatas, menjelaskan hasil pengujian untuk nilai Signal Strength device terhadap AP 2. Jarak 1 meter sebesar $-42,2 \mathrm{dBm}$, jarak 3 meter sebesar $-53,8 \mathrm{dBm}$, jarak 5 meter sebesar $-56 \mathrm{dBm}$ dan jarak 8 meter sebesar $-74,5 \mathrm{dBm}$.

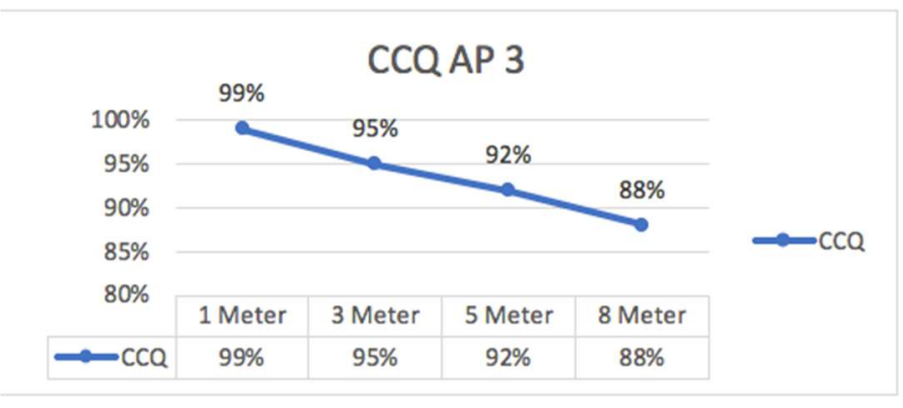

Gambar 11. Grafik CCQ AP 3

Hasil ujicoba menurut grafik diatas, menjelaskan detail nilai CCQ device terhadap AP 3. Jarak 1 meter sebesar 99\%, jarak 3 meter sebesar 95\%, jarak 5 meter sebesar 92\% dan jarak 8 meter sebesar 88\%. 


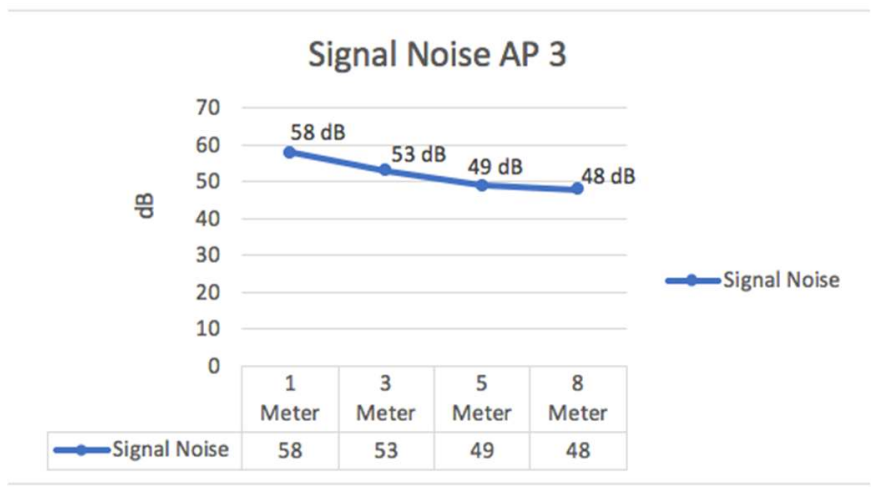

Gambar 12. Grafik Signal to Noise Ratio AP 3

Hasil ujicoba menurut grafik diatas, menjelaskan nilai Signal to Noise Ratio device terhadap AP 3. Jarak 1 meter sebesar $58 \mathrm{~dB}$, jarak 3 meter sebesar $53 \mathrm{~dB}$, jarak 5 meter sebesar $49 \mathrm{~dB}$ dan jarak 8 meter sebesar $48 \mathrm{~dB}$.

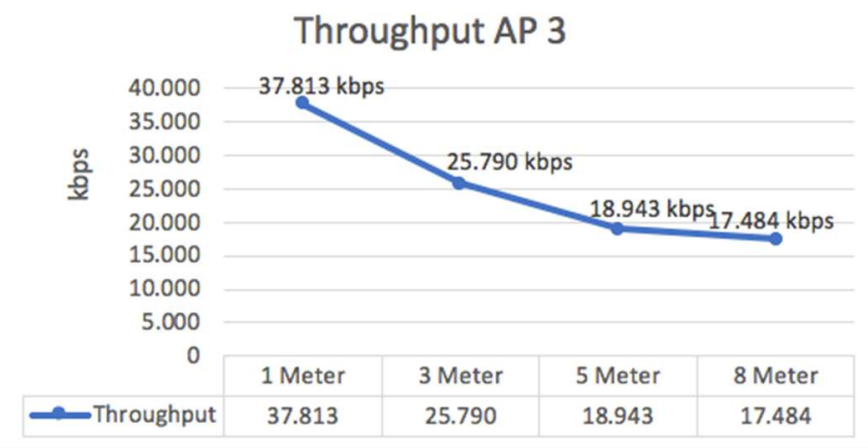

Gambar 13. Grafik Throughput AP 3

Hasil ujicoba menurut grafik diatas, menjelaskan hasil nilai throughput device terhadap AP 3. Jarak 1 meter sebesar 37,813 kbps, jarak 3 meter sebesar 25,790 kbps, jarak 5 meter sebesar 18,943 kbps dan jarak 8 meter sebesar $17,484 \mathrm{kbps}$

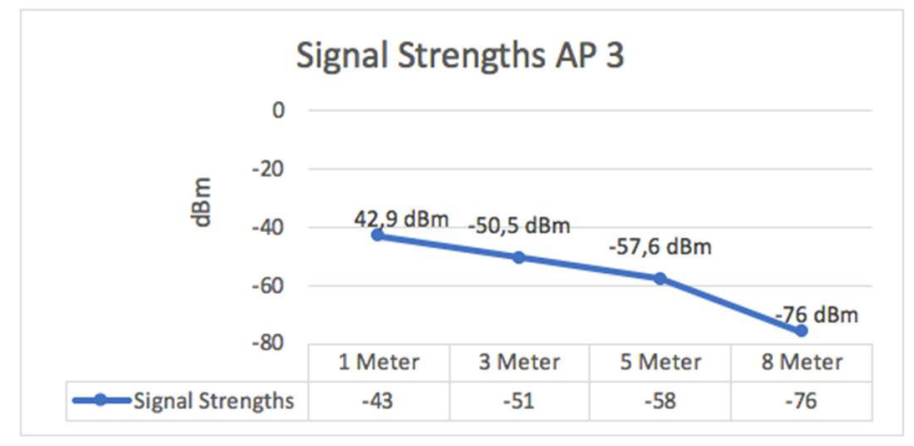

Gambar 14. Grafik Signal Strengths AP 3

Hasil ujicoba menurut grafik diatas, menjelaskan perolehan nilai signal strength device terhadap AP 3. Jarak 1 meter sebesar $-42,9 \mathrm{dBm}$, jarak 3 meter sebesar $-50,5 \mathrm{dBm}$, jarak 5 meter sebesar $-57,6 \mathrm{dBm}$ dan jarak 8 meter sebesar $-76 \mathrm{dBm}$.

\section{KESIMPULAN}

Berdasarkan hasil uji, analisa dan pembahasan, maka dapat disimpulkan sebagai berikut:

1. WDS Mesh mampu mengoptimasi cakupan area $W i-F i$ di UM Jember dengan rata-rata nilai $C C Q=99 \%$, Signal to Noise Ratio $=60 \mathrm{~dB}$, throughput $=67,249 \mathrm{kbps}$, signal strength $=-42,2 \mathrm{dBm}$. Nilai tersebut menggambar tingkat optimalisasi cakupan area penggunaan AP di UM Jember.

2. Pengujian pada AP 1 menghasilkan rata-rata nilai $C C Q$ terbaik $=99 \%$, Signal to Noise Ratio terbaik $=60$ $\mathrm{dB}$, throughput terbaik $=67,249 \mathrm{kbps}$, signal strength terbaik $=-42,2 \mathrm{dBm}$, sedangkan pengujian pada AP 
2 menghasilkan rata-rata nilai $C C Q$ terbaik $=98 \%$, Signal to Noise Ratio terbaik $=58 \mathrm{~dB}$, throughput terbaik $=70,112 \mathrm{kbps}$, signal strength terbaik $=-42,4 \mathrm{dBm}$, pengujian pada AP 3 menghasilkan nilai $C C Q$ terbaik $=99 \%$, Signal to Noise Ratio terbaik $=58 \mathrm{~dB}$, throughput terbaik $=37,813 \mathrm{kbps}$, signal strength terbaik $=-42,9 \mathrm{dBm}$

3. Sesuai hasil pengujian dan analisa perangkat pengguna terhadap AP yang sudah diatur untuk WDS Mesh dengan parameter CCQ, Signal to Noise Ratio, Throughput dan Signal Strength, maka dapat disimpulkan secara keseluruhan memperoleh hasil pengujian yang dikategorikan Excellent (bagus).

\section{REFERENSI}

[1] T. A. Cahyanto, “Analisis deteksi penyusupan pada jaringan komputer menggunakan snort (studi kasus pada Dinas Pariwisata Propinsi Daerah Istimewa Yogyakarta)," Yogyakarta, 2011.

[2] A. Markhadam, "Perancangan dan Analisa Pemanfaatan Access Point Menggunakan Wireless Distribution Sistem," 2016.

[3] D. Arji, D. L. A. Putra, and A. S. KH, “Analisa Kinerja Implementasi Wireless Distribution System Pada Perangkat Access Point 802.11 G Menggunakan Openwrt,” pp. 1-6, 2011.

[4] R. Tulloh, Y. S. Hariyani, M. F. Hafidh, and A. W. Pertiwi, "Papan Informasi Digital Berbasis Raspberry Pi Menggunakan Jaringan Wireless Distribution System,” SIMETRIS, vol. 8, no. 2, pp. 721-730, 2017.

[5] T. A. Cahyanto, "Implementasi Smart Router Berbasis OpenWRT Sebagai Media Untuk File Sharing dan Chatting Pada Laboratorium Terpadu Unmuh Jember," 2018.

[6] T. A. Cahyanto, H. Oktavianto, and A. W. Royan, "Analisis dan Implementasi Honeypot Menggunakan Dionaea Sebagai Penunjang Keamanan Jaringan,” JUSTINDO (Jurnal Sist. dan Teknol. Inf. Indones., vol. 1, no. 2, pp. 86-92, May 2013.

[7] C. T. P. Mikrotik, "Wireless-WDS."

[8] D. Muhammad, G. Indah, and G. Andriana, "An Experimental Connectivity Performance of Simple Wireless Mesh Implementation Using Wireless Distribution System (WDS)," Int. J. Appl. Inf. Technol., vol. 01, no. 02, pp. 0-3, 2017.

[9] G. Sukadarmika, N. I. Er, and N. W. Saputra, “ANALISIS COVERAGE WLAN ( WIRELESS LOCAL AREA NETWORK ) 802 . 11a MENGGUNAKAN OPNET MODELER,” vol. 9, no. 2, 2010.

[10] W. T. Silo, "Analisis Quality of Service pada Transfer Data Audio dan Video Melalui WDS ( Wireless Distribution System )," no. November, 2013.

[11] D. Indra Haerudin et al., "Implementasi Wireless Distribution System (Wds) Pada Hotspot (Studi Kasus : Smk Negeri 1 Kendari)," Online), vol. 3, no. 2, pp. 105-112, 2017.

[12] "Wireless Signal Strength and Noise Levels." [Online]. Available: https://www.watchguard.com/help/docs/help-center/en-US/Content/enUS/Fireware/wireless/ap_wireless_signalstrength_c.html. [Accessed: 06-Feb-2020].

[13] “Wi-Fi Signal Strength: What Is a Good Signal And How Do You Measure It." [Online]. Available: https://eyesaas.com/wi-fi-signal-strength/. [Accessed: 06-Feb-2020].

[14] "Homedale::Wi-Fi / WLAN Monitor - the sz development." [Online]. Available: http://thesz.com/products/homedale/. [Accessed: 06-Feb-2020].

[15] T. W. Sung, C. J. Lee, S. H. Meng, F. T. Lin, Y. C. Sun, and C. S. Yang, "An Algorithm for Improving Network Throughput of Wireless Distribution System," in Proceedings - 2016 3rd International Conference on Computing Measurement Control and Sensor Network, CMCSN 2016, 2017, pp. 178-181.

[16] K. K. Thangadorai, "A Novel Unified Signaling Beacon for Traditional and Mesh WiFi Network," 2019 16th IEEE Annu. Consum. Commun. Netw. Conf., pp. 1-2. 